\title{
The Abating Acerbic - Gastro-oesophageal Reflux Disease
}

\section{Anubha Bajaj* \\ Consultant Histopathologist, A.B. Diagnostics, India}

*Corresponding Author: Anubha Bajaj, Consultant Histopathologist, A.B. Diagnostics, India.

Gastroesophageal reflux disease (GERD) is a chronic disorder wherein gastric contents ascend into the oesophagus. Acid reflux essentially occurs due to inadequate closure of lower oesophageal sphincter.

Associated symptoms appear as an acidic taste, heartburn, foul breath, chest pain, regurgitation, dysphagia, sore throat, water brash, nausea, coughing or respiratory and tooth manifestations.

The condition may engender laryngeal injury, aspiration pneumonia, reflux oesophagitis, oesophageal stricture, Barrett's oesophagus or oesophageal adenocarcinoma.

Factors preponderantly contributing to gastro-oesophageal reflux disease emerge as obesity, pregnancy, hiatal hernia, obstructive sleep apnoea, cholelithiasis or drug intake. Gastric infection with Helicobacter pylori may concur.

Commonly, individuals between the sixth to seventh decade may be implicated although no age of disease emergence is exempt. A specific gender prevalence is absent [1-4].

Morphological alterations associated with the reflux are comprised of oedema, hyperplasia of basal cells, infiltration of lymphocytes, neutrophils, eosinophils, intestinal goblet cell metaplasia, elongation of papillae, attenuation of squamous cell layer, dysplasia or malignant metamorphosis.

An amalgamation of typical clinical symptoms, complications and reflux of gastric contents is mandated for appropriate disease discernment. Additionally, procedures such as gastroscopy, oesophageal pH monitoring, oesophageal manometry or upper gas-
Received: September 21, 2021

Published: October 19, 2012

(C) All rights are reserved by Anubha Bajaj.

\section{Gastroesophageal reflux disease}
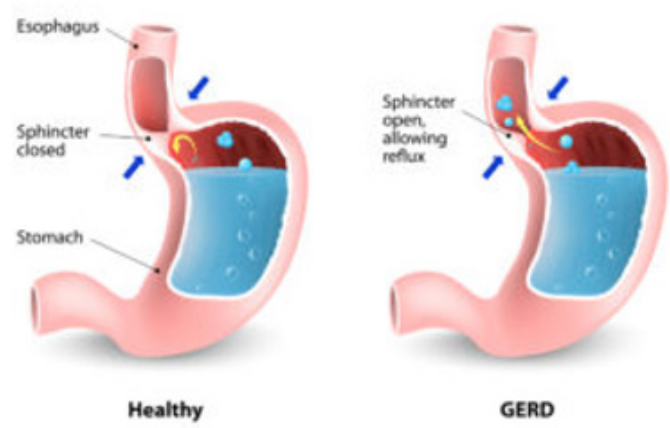

Figure 1: Gastro-oesophageal reflux disease delineating an anomalous lower oesophageal sphincter permitting acid reflux [5].

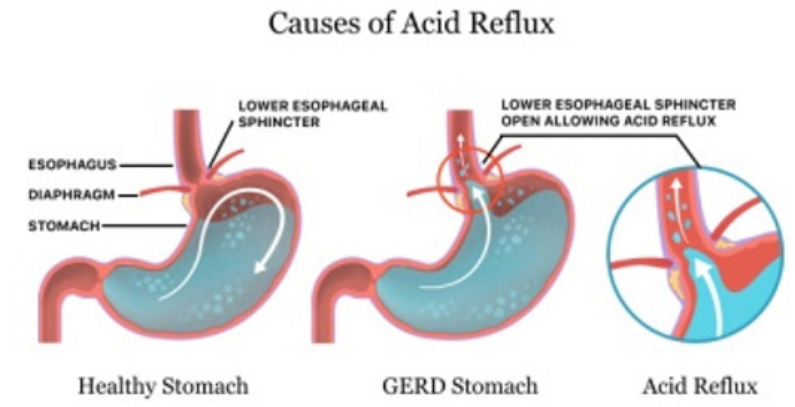

Figure 2: Gastro-oesophageal reflux disease depicting contributory events to acidic reflux [6]. 
trointestinal series can be beneficially employed wherein oesophageal $\mathrm{pH}$ monitoring is a contemporary, optimal and recommended manoeuver. Endoscopy or oesophago-gastroduodenoscopy can be employed to exclude epithelial metaplasia and malignant metamorphosis.

Cogent therapeutic measures are comprised of appropriate dietary and lifestyle modifications, medications or surgical intervention. Agents such as antacids, $\mathrm{H}_{2}$ receptor blockers, proton pump inhibitors, prokinetics or $\mathrm{GABA}_{\mathrm{B}}$ receptor agonists may be employed to treat gastro-oesophageal reflux disease.

Additionally, surgical procedures as fundoplication or oesophagogastric dissociation are associated with decimated failure or proportionate reoccurrence. Transoral incisionless fundoplication is a contemporary, efficacious technique for treating gastro-oesophageal reflux disease with sustained benefits.

\section{Bibliography}

1. Labenz J., et al. “Gastroösophageale Refluxkrankheit- Update 2021 [Gastro-oesophageal reflux disease-update 2021]". Internist (Berl) 61.12 (2020): 1249-1263.

2. Săraru ER., et al. "Advances in the diagnosis of GERD". Romanian Journal of Internal Medicine 59.1 (2021): 3-9.

3. McKinley SK., et al. "Surgical treatment of GERD: systematic review and meta-analysis". Surgery Endoscopy 35.8 (2021): 4095-4123.

4. Clarrett DM and Hachem C. "Gastroesophageal Reflux Disease (GERD)”. Missouri Medicine 115.3 (2018): 214-218.

5. Image Courtesy: Tulsa endoscopy centre.

6. Image Courtesy: Drugwatch.com.

\section{Volume 4 Issue 11 November 2021}

\section{(C) All rights are reserved by Anubha Bajaj.}

